\title{
Lung function, respiratory illness, and passive smoking in British primary school children
}

\author{
R J Rona, S Chinn
}

\begin{abstract}
Background Many studies have reported a significant association between parents' smoking and reduced lung function in their children, but often the association has been found to be significant only in relation to maternal smoking. There have been few epidemiological studies on this topic in Britain.

Methods Spirometry, in 2756 children aged 6.50-11.99 years, was carried out in a representative sample of English children, an inner city and ethnic minority sample, and a Scottish sample. Forced vital capacity (FVC), forced expiratory volume in one second $\left(F E V_{1}\right)$, and forced expiratory flow rates of $25-75 \%$ and $75-$ $85 \%\left(\right.$ FEF $_{25-75}$ and FEF $\left._{75-85}\right)$ were measured and standardised scores obtained separately for the English representative sample, the Scottish sample and subgroups in the inner city sample, white and Afro-Caribbean children and those originating from the Indian subcontinent. Multiple regression analyses were used to assess associations of FVC, FEV FEF $_{25-75}$ and FEF $_{75-85}$ with the passive smoking and respiratory illness, with adjustment for a large number of potential confounders. Passive smoking was defined in terms of reported number of cigarettes smoked at home by each parent. The respiratory symptoms and illnesses assessed were wheeze, asthma and bronchitis attacks, cough in the morning, and cough at any other time as reported by parents.
\end{abstract}

Results Maternal smoking, but not paternal smoking, was associated with reduced $\mathrm{FEF}_{25-75}$ and $\mathrm{FEF}_{75-85}$ in boys. No association was found between passive smoking and lung function in girls, but in an analysis including both sexes the interaction of sex and parental smoking on lung function was not significant. With few exceptions, $\mathrm{FEV}_{1}, \mathrm{FEF}_{25-75}$ and $\mathrm{FEF}_{75-85}$ were reduced in children with wheeze and asthma attacks.

Conclusions The effect of passive smoking may depend on the close contact of a parent with a susceptible child as only maternal smoking in boys was significantly associated with impaired lung function. However, this explanation remains unsubstantiated. A parent's report of wheeze and asthma attacks in the child is reflected in reduced lung function.

(Thorax 1993;48:21-25)
In the United States there have been a large number of studies exploring the relation between lung function in children and the environment. ${ }^{1-10}$ In Britain studies of this subject were largely carried out in the $1960 \mathrm{~s},{ }^{11}$ and were limited to a small geographical area ${ }^{12}$ or restricted to a specific issue such as dampness or outdoor pollution..$^{13} \mathrm{~A}$ recently published paper reported the association between salivary cotinine and spirometric indices in seven year old children. ${ }^{14}$ Many studies have focused on the association between lung function and passive smoking and respiratory illness in childhood and the most frequent social factors included in the studies have been parents' education level ${ }^{23710}$ and occupation of the head of the household. ${ }^{7}$ Social factors, however, have been shown to be only marginally associated with lung function ${ }^{2}$ or not associated at all. ${ }^{37}$ Most studies exploring the association between passive smoking and lung function have reported a significant relationship..$^{2-57-101415}$ A few studies, especially those carried out in the 1970s, have failed to show an association between lung function and passive smoking. ${ }^{4616}$ Moreover, in those studies where significant associations have been reported, these have been confined to either maternal smoking ${ }^{351015}$ or to children of one $\operatorname{sex}^{2717}$ or of a limited age group. ${ }^{2}$ It is therefore of interest to explore the extent of the relationship between respiratory illness, passive smoking, and lung function in Britain when the data are adjusted for potentially confounding biological and social factors.

In the National Study of Health and Growth (NSHG), a nutritional surveillance system, ${ }^{18}$ data were collected on lung function from a substantial subsample of study areas in England and Scotland in 1987 and 1988. The sample included a range of socioeconomic, ethnic and geographical groups in the population. The aim of the analysis was to assess the contribution of respiratory illness and passive smoking to variation in lung function, with adjustment for potentially confounding social and biological factors. The factors associated with respiratory illness have been reported previously. ${ }^{19-21}$

\section{Methods}

Information on lung function was obtained for children aged 6.50-11.99 years from a subsample of areas of the NSHG in 1987 and $1988 .^{22}$ The subsample included data from a representative sample of English children surveyed in 1988 , an inner city and ethnic minority sample surveyed in 1987, and a Scottish representative sample assessed in 1987 and 1988. The total
Hospital Campus

R J Rona

Reprint requests to:

Dr R J Rona

Accepted 28 May 1992 
number of eligible children was 2486 in the English representative sample, 1895 in the English inner city sample and 634 in the Scottish representative sample. Within the inner city sample, one area had a high proportion of children of Afro-Caribbean origin and three had a high proportion of children originating in the Indian subcontinent. Children were classified into the ethnic groups Caucasian, Afro-Caribbean, Urdu, Gujarati, Punjabi, other Indian subcontinent, and other or not known. ${ }^{18}$

Lung function was measured with a spirometer (Vitalograph Model S) with a spirogram and digital printout. After calibration of the machine and demonstration of its use, each child had three recorded attempts without a noseclip with a minimum exhalation time of 1.5 seconds. These were recorded unless the fieldworker judged a blow to be in error from the spirogram. Children with reported severe diseases such as a heart condition were not included. Children with asthma were included and use of inhaler in the morning was recorded, but the data were excluded from the initial analysis. From the total of eligible children the following exclusions were made: 99 for use of inhaler, 54 for leak in tube, 15 for severe disease, five for refusal to participate, 271 for absenteeism during fieldwork and 153 for no valid blow. The total number of children with at least one valid blow was $2235(89.9 \%)$ of the English representative sample, $1595(84 \cdot 2 \%)$ of the inner city area, and $499(78.7 \%)$ of the Scottish representative sample. The lower percentage of children in the Scottish sample was due to a leaking spirometer tube that excluded 54 children from analysis.

For each child forced vital capacity (FVC), forced expiratory volume in one second $\left(\mathrm{FEV}_{1}\right)$, forced expiratory flow rates between $25 \%$ and $75 \%\left(\mathrm{FEF}_{25-75}\right)$ and between $75 \%$ and $85 \%\left(\mathrm{FEF}_{75-85}\right)$ were recorded. All data from the best blow, defined as the greatest sum of FVC and $\mathrm{FEV}_{1}$, were analysed. Height was measured on a Holtain Stadiometer to the last complete $0.1 \mathrm{~cm}$, as described by Tanner et $a l .^{23}$ Weight was recorded to within $100 \mathrm{~g}$ with electronic scales (Soehnle) and triceps skinfold was measured by the method recommended by Tanner and Whitehouse. ${ }^{24}$

Distributions of residuals from multiple regression analyses of $\ln$ (lung function), where $\ln =\log _{\mathrm{e}}$ on $\ln$ (height) and $\ln$ (age), were assessed for normality, and the method of Bland $e t$ $a l^{25}$ was then used to obtain standardised scores. The logarithmic transformation stabilised variances and antilogging the residuals produced near normal distributions in the English representative sample. ${ }^{22}$ Standard deviation scores were calculated by taking the difference between actual $\ln$ (lung function) and the predicted value from appropriate equations, antilogging the result, taking the difference between this figure and the mean of the distribution of antilogged residuals, and dividing by the standard deviation. The same procedure was used to calculate standard deviation scores separately for white children in the inner city areas, the Scottish sample, the
Afro-Caribbean group and the groups originating from the Indian subcontinent combined (referred to here as Asians).

Multiple regressions were performed with FVC, $\mathrm{FEV}_{1}, \mathrm{FEF}_{25-75}$, and $\mathrm{FEF}_{75-85}$ standard deviation scores as dependent variables to estimate the effect of passive smoking on lung function of boys and girls. The additional independent continuous variables were $\ln$ (weight), $\ln$ (triceps skinfold), birthweight, reported parental heights, and mother's age at child's birth. The categorical variables were the sociodemographic variables family size, father's social class, overcrowding, one parent family, mother's education, father's employment status, type of cooking fuel, study area, and type of school meals. The latter variable identified children receiving free school meals on socioeconomic grounds. The variables height, age, and ethnic background were not included in the analyses as the standard deviation scores were specific for each ethnic group and were obtained adjusted for height and age. The association of passive smoking and lung function was assessed for paternal, maternal, and total home smoking in separate models, including and excluding the respiratory symptoms wheeze, asthma attacks in last year, bronchitis attacks in last year, cough first thing in the morning, and cough at other times. The respiratory symptoms were analysed separately as independent variables, allowing for total home smoking and the other variables included in the previous analysis. In a separate analysis the relationships of FVC, $\mathrm{FEV}_{1}, \mathrm{FEF}_{25-75}$, and $\mathrm{FEF}_{75-85}$ to reported wheeze according to exposure to passive smoking was assessed.

\section{Results}

Table 1 gives the parents' combined daily cigarette consumption while in the home by ethnic group and country of residence, including one parent families. Inner city white parents smoked most heavily. There were very few children in the Asian groups exposed to smoking in the home of more than 15 cigarettes per day, as smoking is predominantly a male activity in these groups. Only 13 out of 681 Asian mothers were smokers. Gujarati parents smoked least of the Asian groups (not shown). For Afro-Caribbean children, maternal smoking was a more important component of total parental smoking because there was a larger percentage of one parent families. In the representative sample, Scottish parents smoked more than English parents.

Children with missing values for continuous independent variables were omitted from the analysis. From a total of 4329 children with at least one valid blow, $2756(63.7 \%)$ were included in the analysis. An analysis of the height and age associations with lung function and the differences in lung function between ethnic groups has been reported previously. ${ }^{22}$ The independent variables explained from $7.9 \%\left(\mathrm{FEF}_{75-85}\right)$ to $11.9 \%\left(\mathrm{FEF}_{25-75}\right)$ of the variation in standard deviation scores, with intermediate values for $\mathrm{FEV}_{1}$ and FVC. Dif- 
Table 1 Percentage exposure to cigarette smoking in the home of children eligible for lung function measures, by ethnic group in English inner city areas, and in the English and Scottish representative samples

\begin{tabular}{|c|c|c|c|c|c|c|}
\hline \multirow{3}{*}{$\begin{array}{l}\text { Parents' daily } \\
\text { cigarette consumption } \\
\text { in the home }\end{array}$} & \multicolumn{5}{|l|}{ England } & \multirow{3}{*}{$\begin{array}{l}\text { Scottish } \\
\text { representative } \\
\text { sample: } \\
\text { white }\end{array}$} \\
\hline & \multirow{2}{*}{$\begin{array}{l}\text { Representative } \\
\text { sample }\end{array}$} & \multicolumn{4}{|c|}{ Inner city areas } & \\
\hline & & White & $\begin{array}{l}\text { Afro- } \\
\text { Caribbean }\end{array}$ & Asian * & Others & \\
\hline $\begin{array}{l}0 \\
1-4 \\
5-14 \\
15-24 \\
25-34 \\
35 \text { or more }\end{array}$ & $\begin{array}{r}60 \cdot 0 \\
4 \cdot 2 \\
18 \cdot 1 \\
11 \cdot 7 \\
3 \cdot 5 \\
2 \cdot 4\end{array}$ & $\begin{array}{r}37 \cdot 8 \\
2 \cdot 2 \\
26 \cdot 8 \\
19 \cdot 3 \\
7 \cdot 4 \\
6 \cdot 4\end{array}$ & $\begin{array}{r}63 \cdot 8 \\
8 \cdot 3 \\
22 \cdot 2 \\
4 \cdot 2 \\
1 \cdot 3 \\
1 \cdot 9\end{array}$ & $\begin{array}{r}64 \cdot 6 \\
9 \cdot 1 \\
19 \cdot 8 \\
5 \cdot 5 \\
0 \cdot 8 \\
0 \cdot 3\end{array}$ & $\begin{array}{r}54 \cdot 1 \\
5 \cdot 7 \\
24 \cdot 8 \\
12 \cdot 1 \\
1.9 \\
1 \cdot 3\end{array}$ & $\begin{array}{r}51 \cdot 7 \\
2 \cdot 3 \\
22 \cdot 2 \\
16 \cdot 1 \\
4 \cdot 6 \\
3 \cdot 2\end{array}$ \\
\hline Total No of children & 2205 & 497 & 160 & 658 & 157 & 571 \\
\hline
\end{tabular}

*Gujarati, Punjabi, Urdu and other children originating in the Indian subcontinent were grouped together.

ferences in explained variation between sexes were minimal.

Most of the independent confounding variables in the analysis were not consistently related to all four measurements of lung function, or were not consistent in boys and girls. The only exceptions were birthweight, which was positively associated with most measures of lung function in both sexes, and study area in boys. Of the other significant associations, girls whose fathers were in the manual social class had lower $\mathrm{FEF}_{25-75}$ and $\mathrm{FEF}_{75-85}$ measurements $(\mathrm{p}<0.01)$ than other girls, and girls from one parent families had lower $\mathrm{FEV}_{1}$ values $(\mathrm{p}<0.05)$ than other girls. These associations are only indicative, as the analysis was designed to adjust sufficiently for confounding variables rather than to investigate these relationships directly.

Table 2 shows the regression coefficients and their standard errors for measures of lung function on passive smoking, adjusted for the factors specified in the "Methods" section but excluding respiratory symptoms as these may be the mechanism for impaired lung function. The only significant associations detected were between maternal home smoking and reduced $\mathrm{FEF}_{25-75}$ and $\mathrm{FEF}_{75-85}$ in boys. Two other associations were of borderline significance in boys- $-\mathrm{FEV}_{1}$ with maternal home smoking, and $\mathrm{FEF}_{25-75}$ with total home smoking ( $\mathrm{p}<0 \cdot 1$ ). Although not significantly different from zero, all other regression coefficients of lung function on maternal smoking were negative. In contrast, for paternal smoking at home most of the regression coefficients were positive. Little change in the regression coefficients occurred when respiratory symptoms were included in the model. In an analysis including both sexes, the interaction of sex and passive smoking was not significantly related to any of the measures of lung function. The differing effect of maternal and paternal smoking was confirmed by an analysis of both sexes in which both the sum and difference of maternal and paternal home smoking were used as the measures of passive smoking. The regression coefficient for the difference was significant $(\mathrm{p}<0.05)$ for $\mathrm{FEV}_{1}$ and $\mathrm{FEF}_{75-85}$ and of borderline significance $(\mathrm{p}<0 \cdot 1)$ for $\mathrm{FEF}_{25-75}$.

Children with occasional and frequent wheeze and asthma attacks had significantly decreased lung function (generally $\mathrm{FEV}_{1}$, $\mathrm{FEF}_{25-75}$, and $\mathrm{FEF}_{75-85}$ ) (table 3). Bronchitis attacks in girls were associated with lower lung function. Respiratory conditions were consistently negatively related to lung function with the exception of FVC. The possible increased effect of parental smoking on lung function in children with wheeze was analysed in a sample of 181 boys and 120 girls. In boys, there was a significant reduction in $\mathrm{FEV}_{1}(\mathrm{p}<0.05)$ and lower FVC and $\mathrm{FEF}_{25-75}$, of borderline significance $(\mathrm{p}<0.1)$, with increasing exposure to parental cigarette smoke. This was not observed in girls with wheeze.

\section{Discussion}

In this study the lung function of a wide range of groups of children has been measured to assess its relation with respiratory illness and parental passive smoking, adjusting for social

Table 2 Standard deviation scores for regression coefficients (SE) of lung function on measures of passive smoking adjusted for social and biological factors (see under "Methods"), excluding respiratory symptoms

\begin{tabular}{llllll}
\hline & $n$ & $F V C$ & $F E V_{1}$ & $F E F_{25-75}$ & $F E F_{75-85}$ \\
\hline Boys & & & & & \\
Total parental home smoking & 1429 & $0.0012(0.0029)$ & $-0.0021(0.0029)$ & $-0.0053(0.0029) \dagger$ & $-0.0044(0.0029)$ \\
Maternal home smoking & 1470 & $-0.0016(0.0044)$ & $-0.0074(0.0043) \dagger$ & $-0.0128(0.0043)^{\star \star}$ & $-0.0100(0.0044)^{\star}$ \\
Paternal home smoking & 1388 & $0.0042(0.0046)$ & $0.0038(0.0046)$ & $0.0015(0.0046)$ & $0.0032(0.0047)$ \\
Girls & & & & & \\
Total parental home smoking & 1309 & $0.0015(0.0029)$ & $-0.0010(0.0030)$ & $-0.0047(0.0030)$ & $-0.0011(0.0030)$ \\
Maternal home smoking & 1342 & $-0.0013(0.0044)$ & $-0.0047(0.0045)$ & $-0.0055(0.0045)$ & $-0.0029(0.0046)$ \\
Paternal home smoking & 1273 & $0.0071(0.0045)$ & $0.0058(0.0046)$ & $-0.0020(0.0047)$ & $0.0034(0.0047)$ \\
\hline
\end{tabular}

There was a small difference in the number of valid blows by measurement, with usually fewest observations for $\mathrm{FEF}_{75-8}$ The number of observations given is the minimum for the four measures of lung function. It is greater for total than for paternal home smoking because the former included one parent families.

${ }^{\star} \mathrm{p}<0.05 ;{ }^{\star \star} \mathrm{p}<0.01 ; \mathrm{p}<0.1$ 
Table 3 Standard deviation scores for regression coefficients (SE) of differences in lung function between groups of children defined by respiratory conditions each adjusted for passive smoking (total parental smoking at home), NSHG area and biological and social variables (see Methods)

\begin{tabular}{|c|c|c|c|c|}
\hline $\begin{array}{l}\text { Respiratory } \\
\text { condition/symptoms }\end{array}$ & $\begin{array}{l}F V C \\
(n=1443)\end{array}$ & $\begin{array}{l}F E V_{1} \\
(n=1443)\end{array}$ & $\begin{array}{l}F E F_{25-75} \\
(n=1438)\end{array}$ & $\begin{array}{l}F E F_{75-85} \\
(n=1429)\end{array}$ \\
\hline \multicolumn{5}{|l|}{ Boys } \\
\hline Occasional wheeze & $0.02(0.09)$ & $-0 \cdot 18(0 \cdot 09)^{\star}$ & $-0.34(0.09)^{\star \star \star}$ & $-0.32(0.09)^{\star \star \star}$ \\
\hline Wheeze most days or nights & $-0 \cdot 11(0 \cdot 17)$ & $-0 \cdot 39(0 \cdot 17)^{\star}$ & $-0 \cdot 38(0 \cdot 17)^{\star}$ & $-0 \cdot 21(0 \cdot 17)$ \\
\hline Asthma attacks & $0 \cdot 14(0 \cdot 12)$ & $-0 \cdot 27(0 \cdot 12)^{\star}$ & $-0.61(0 \cdot 11)^{\star \star \star}$ & $-0.52(0 \cdot 12)^{\star \star \star}$ \\
\hline Bronchitis attacks & $0.00(0 \cdot 18)$ & $-0.09(0 \cdot 18)$ & $-0.02(0 \cdot 17)$ & $-0.04(0.18)$ \\
\hline Cough first thing & $-0.04(0.13)$ & $-0 \cdot 23(0 \cdot 13)^{\star}$ & $-0 \cdot 14(0 \cdot 13)$ & $-0 \cdot 12(0 \cdot 13)$ \\
\hline Cough at other times & $0.01(0.09)$ & $-0 \cdot 13(0 \cdot 09)$ & $-0.23(0.09)^{\star}$ & $-0 \cdot 12(0.09)$ \\
\hline \multicolumn{5}{|l|}{ Girls } \\
\hline Occasional wheeze & $-0 \cdot 22(0 \cdot 11)^{\star}$ & $-0 \cdot 38(0 \cdot 11)^{\star \star \star}$ & $-0.42(0 \cdot 11)^{\star \star \star}$ & $-0 \cdot 17(0 \cdot 12)$ \\
\hline Wheeze most days or nights & $0 \cdot 23(0 \cdot 19)$ & $-0 \cdot 14(0 \cdot 19)$ & $-0.49(0 \cdot 19)^{\star}$ & $-0.58(0 \cdot 20)^{\star \star}$ \\
\hline Asthma attacks & $0.01(0 \cdot 16)$ & $-0 \cdot 34(0 \cdot 17)^{\star}$ & $-0.60(0 \cdot 17)^{\star \star \star}$ & $-0.45(0 \cdot 17)^{\star \star}$ \\
\hline Bronchitis attacks & $-0.41(0.23) \dagger$ & $-0 \cdot 48(0 \cdot 24)^{\star}$ & $-0.40(0.24) \dagger$ & $-0.49(0 \cdot 24)^{\star}$ \\
\hline Cough first thing & $-0 \cdot 15(0 \cdot 13)$ & $-0 \cdot 20(0 \cdot 14)$ & $-0 \cdot 19(0 \cdot 14)$ & $-0 \cdot 27(0 \cdot 14)^{\star}$ \\
\hline Cough at other times & $-0 \cdot 12(0 \cdot 10)$ & $-0 \cdot 12(0 \cdot 10)$ & $0 \cdot 01(0 \cdot 10)$ & $-0 \cdot 07(0 \cdot 10)$ \\
\hline
\end{tabular}

tp $<0.01 ;{ }^{\star} \mathrm{p}<0.05 ;{ }^{\star \star} \mathrm{p}<0.01 ;{ }^{\star \star \star} \mathrm{p}<0.001$.

factors and other characteristics of the child such as age, sex, and height. In a previous paper a methodology for adjusting for age and height was proposed ${ }^{22}$ and has been the basis for the current analysis. All the children with at least one valid blow were included in the analysis. With this method, Afro-Caribbean children had lower lung function values than white children, whether living in inner city areas or from a representative sample, whereas children originating in the Indian subcontinent had lung function values intermediate between those of the Afro-Caribbean and the white children. ${ }^{22}$ Several studies have reported similar findings for differences between AfroCaribbean and white children, ${ }^{26-28}$ although some that have looked at $\mathrm{FEV}_{1} / \mathrm{FVC}$ ratios have failed to find any difference between the groups. ${ }^{27}$

We confirm that children whose parents report wheeze or asthma attacks in the child have significantly lower lung function test results than children without these symptoms. ${ }^{4529}$ This study shows that a large range of potential confounding variables do not reduce the negative significant association between $\mathrm{FEV}_{1}, \mathrm{FEF}_{25-75}$, and $\mathrm{FEF}_{75-85}$ and symptoms of asthma. This study also asserts the value of parents' information on children's respiratory illness in surveys. Even children who were reported by parents to have occasional wheeze had significantly lower lung function measurements than those who were not. However, in our study children with severe wheeze did not have consistently more impaired lung function than children with occasional wheeze. Other respiratory symptoms may be associated with $\mathrm{FEV}_{1}, \mathrm{FEF}_{25-75}$, and $\mathrm{FEF}_{75-85}$ given their consistent negative coefficient, but they rarely achieved significant levels. FVC was the only measure of lung function not related to respiratory illness.

The associations between passive smoking and lung function were inconsistent. Our results are consistent with many reports which show that maternal and not paternal smoking is significantly associated with some measures of lung function. ${ }^{3571014}$

A pattern of association between lung function and passive smoking in boys only was also reported by Tashkin et al. ${ }^{7}$ Their findings invite interpretation on the potential differential sus- ceptibility of boys and girls in line with a suggestion proposed by Taussig et al ${ }^{29}$ that the mechanical properties of the lung may be related to the different prevalence for lower respiratory tract illnesses and asthma in the two sexes. In this study, the regression coefficients for each of the lung function measures are substantially smaller in girls than in boys. The interaction effect of sex and passive smoking on lung function in the total group was not significant. Therefore the hypothesis of differential susceptibility between sexes is not supported by this analysis.

The amount of time spent by each parent with a child can explain the association of the child's lung function with maternal smoking but not paternal smoking. In China, where smoking is mainly a male activity, paternal smoking has been found to be associated with children's lung function. ${ }^{16}$ Overcrowding, house ventilation, and the amount smoked by each parent at home can affect the relationship between passive smoking and lung function. In this study overcrowding was unrelated to lung function and number of children in the family was related only to FVC in girls, a measure not associated with passive smoking in our study. Lebowitz and Holberg found maternal smoking related to $\mathrm{FEV}_{1}$ in Boston but not in Tucson (Arizona). ${ }^{4}$ They ascribed the difference to a ventilation phenomenon. In a study in Los Angeles, Tashkin et $a l^{7}$ detected an association between maternal smoking and the child's lung function but the association tended to disappear in older adolescent boys.

On the whole, our study illustrates the difficulties in making generalisations about the association between lung function and passive smoking in childhood. The effect of passive smoking on lung function is likely to depend on the amount of time spent by the smoker with the child, the number of cigarettes smoked, and the child's susceptibility. We have included a large number of confounding variables that could have explained a spurious relationship between lung function and passive smoking.

In our analysis, boys with wheeze exposed to parents' smoking had more impaired lung function in terms of $F E V_{1}$ and possibly FVC and $\mathrm{FEF}_{25-75}$ than boys with wheeze whose parents did not smoke. This result provides further evidence that parental smoking may 
worsen the functional state of asthmatic children. However, it is puzzling that the association between lung function and parental smoking appeared weaker in girls.

Of the many social, environmental, and demographic factors included in the study as possible confounders, few showed an association with lung function measurement. In girls, lung function was associated with father's social class. In addition, the number of children in the family was associated with FVC in girls. Social class has been shown to be associated with peak expiratory flow rates. ${ }^{11}$ The study which demonstrated this relation, however, adjusted for few potential confounding variables. In the United States, few studies have included measures of socioeconomic level when assessing lung function. The exceptions are parents' education (a factor not associated with lung function in the current study), and occasionally occupation of the head of the household. ${ }^{7}$ The socioeconomic environment may have a small effect on lung function which is independent of intermediate associations with respiratory symptoms and passive smoking-both of which are more prevalent in poor sectors of the community. Three factors besides respiratory symptoms and passive smoking which may explain the association between social factors and lung function are housing conditions, outdoor pollution, and undernutrition, but none has been confirmed in the literature. Strachan and Sanders ${ }^{13}$ were unable to show any relationship between home dampness, humidity, and temperature and lung function. With regard to nutritional state, we have adjusted for anthropometric measures such as weight and triceps skinfold thickness, and height has been included in the calculation of standard deviation scores of each lung function measurement. With respect to outdoor pollution, Ware et $a l^{30}$ reported no effect of sulphur dioxide and suspended particles on lung function.

Even after the inclusion of a large number of independent variables to assess variation in lung function, individual characteristics of the study areas selected were significantly associated with lung function in boys. It is uncertain whether this indicates additional environmental effects on lung function.

In conclusion, this study has shown that parents' information about a child's asthma is associated with measures of lung function and that passive smoking can affect lung function. Close contact of the smoker with the child may be critical in damaging the growth of the lung. It must be recognised, however, that the mechanism of the association between a child's lung function and maternal smoking but not paternal smoking remains unexplained.

The authors thank all parents, children and helpers in the areas and schools in the study. We thank our colleagues on the study team and Professor $W W$ Holland for their support, and Ms P Mortley for producing the manuscript. The study is funded Mortley for producing the manuscript. The study is funded
through the Department of Health and the Scottish Home and through the Departm
Health Department.

1 Brunekreef B, Dockery DW, Speizer FE, Ware JH, Spengler JD, Ferris BG. Home dampness and respiratory morbidity in children. Am Rev Respir Dis 1989;140: 1363-7.

2 Burchfiel CM, Higgins MW, Keller JB, Howatt WF, Butler WJ, Higgins ITT. Passive smoking in childhood. Respiratory conditions and pulmonary function in Tecumseh,
Michigan. Am Rev Respir Dis 1986;133:966-73.

3 Hasselblad V, Humble CG, Graham MG, Anderson HS. Indoor environmental determinants of lung function in children. Am Rev Respir Dis 1981;123:479-85.

4 Lebowitz MD, Holberg CJ. Effects of parental smoking and other risk factors on the development of pulmonary function in children and adolescents. Analysis of two longitudinal population studies. Am J Epidemiol 1988; 128:589-97.

5 Lebowitz MD, Holberg CJ, Knudson RJ, Burrows B. Longitudinal study of pulmonary function development in childhood, adolescence, and early adulthood. Development of pulmonary function. Am Rev Respir Dis 1987; 136:69-75.

6 Schilling RSF, Letai AD, Hui SL, Beck GJ, Schoenberg JB, Bouhuys A. Lung function, respiratory disease and smoking in families. Am J Epidemiol 1977;106:274-83.

7 Tashkin DP, Clark VA, Simmons M, Reems C, Coulson AH, Bourque LB, et al. The UCLA population studies of chronic obstructive respiratory disease. VII. Relationship between parental smoking and children's lung function. Am Rev Respir Dis 1984;129:891-7.

8 Tager IB, Weiss ST, Munoz A, Rosner B, Speizer FE. Longitudinal study of the effects of maternal smoking on pulmonary function in children. N Engl J Med 1983; 309:699-703.

9 Tager IB, Weiss ST, Rosner B, Speizer FE. Effect of parental cigarette smoking on the pulmonary function of children. Am J Epidemiol 1979;110:15-26.

10 Ware JH, Dockery DW, Spiro A III, Speizer FE, Ferris BG Jr. Passive smoking, gas cooking, and respiratory health of children living in six cities. Am Rev Respir Dis 1984; 129:366-74.

11 Holland WW, Halil T, Bennett AE, Elliott A. Factors influencing the onset of chronic respiratory disease. $B M J$ 1969;ii:205-8.

12 Yarnell JWG, St Leger AS. Respiratory infections and their influence on lung function in children: a multiple regression analysis. Thorax 1981;36:847-51.

13 Strachan DP, Sanders CH. Damp housing and childhood asthma; respiratory effects of indoor air temperature and relative humidity. J Epidemiol Community Health 1989; 43:7-14

14 Strachan DP, Jarvis MJ, Feyerabend C. The relationship of salivary cotinine to respiratory symptoms, spirometry, and exercise-induced bronchospasm in seven-year-old children. Am Rev Respir Dis 1990;142:147-51.

15 Kauffmann F, Tager IB, Munoz A, Speizer FE. Familial factors related to lung function in children aged 6-10 years. Results from the PAARC epidemiologic study. Am J Epidemiol 1989;129:1289-99.

16 Leeder SR, Corkhill RT, Wysocki MJ, Holland WW, Colley JRT. Influence of personal and family factors on ventilatory function of children. J Epidemiol Community Health 1976;30:219-24.

17 Chen $\mathrm{Y}, \mathrm{Li} \mathrm{W}-\mathrm{X}$. The effect of passive smoking on children's pulmonary function in Shanghai. Am J Public Health 1986;76:515-8.

18 Rona RJ, Chinn S. National Study of Health and Growth: social and biological factors associated with height of children from ethnic groups living in England. Ann Hum Biol 1986;13:453-71.

19 Chinn S, Rona RJ. Quantifying the health effects of passive smoking on British children aged 5-11 years. J Epidemiol Community Health 1991;45:188-94.

20 Melia RJW, Chinn S, Rona RJ. Respiratory illness and home environment of ethnic groups. BMJ 1988;296:1438-41.

21 Rona RJ, Florey C du V. National Study of Health and Growth: respiratory symptoms and height in primary school children. Int J Epidemiol 1980;9:35-43.

22 Chinn S, Rona RJ. Height and age adjustment for crosssectional studies of pulmonary function in children aged 6 to 11 years. Thorax 1992;47:707-14.

23 Tanner JM, Whitehouse RH, Takaishi M. Standards from birth to maturity for height, weight, height velocity and weight velocity. British children 1965. Arch Dis Child 1966;41:454-71.

24 Tanner JM, Whitehouse RH. Revised standards for triceps and subscapular skinfolds in British children. Arch Dis Child 1975;50:142-5.

25 Bland JM, Peacock JL, Anderson HR, Brook OG, de Curtis $M$. The adjustment of birthweight for very early gestational ages: two related problems in statistical analysis. Appl Stat 1990;39:229-39.

26 Dockery DW, Berkey CS, Ware JH, Speizer FE, Ferris BG Jr. Distribution of forced vital capacity and forced expiratory volume in one second in children 6 to 11 years of age. Am Rev Respir Dis 1983;128:405-12.

27 Patrick JM, Patel A. Ethnic differences in the growth of lung function in children: a cross-sectional study in inner-city Nottingham. Ann Hum Biol 1986;13:307-15.

28 Schwartz J, Katz SA, Fegley RW, Tockman MS. Sex and race differences in the development of lung function. $\mathrm{Am}$ Rev Respir Dis 1988;138:1415-21.

29 Taussig LM, Cota K, Kaltenborn W. Different mechanical properties of the lung in boys and girls. Am Rev Respir Dis 1981;123:640-3.

30 Ware JH, Ferris BG, Dockery DW, Spengler JD, Stram DO. Effects of ambient sulfur oxides and suspended particles on respiratory health of preadolescent children. Am Rev Respir Dis 1986;133:834-42. 